\title{
A Macroeconomia do crescimento sustentado
}

\author{
José Luís da Costa Oreiro ${ }^{8}$ \\ Marcelo Luiz. Curado 9 \\ Fábio Dória Scatolin ${ }^{10}$ \\ José Gabriel Porcile Meirelles ${ }^{11}$ \\ Luciano Nakabashi $i^{12}$ \\ Breno Pascualote Lemos ${ }^{13}$ \\ Rodrigo Ayres Padilha ${ }^{14}$
}

Nos últimos 25 anos a economia brasileira vem crescendo a uma taxa média de cerca de 2,6\% a.a, valor bastante inferior a média observada no período 1950-1980 e abaixo da taxa média de crescimento obtida por outros países emergentes como, por exemplo, Rússia, China e Índia. Tendo em vista um crescimento populacional da ordem de 1,5\% a.a, o PIB per-capita tem crescido nos últimos anos a uma taxa pouco superior a 1\% a.a. Nesse ritmo levará quase 70 anos para que a renda per-capita brasileira dobre de tamanho, igualando-se ao nível de renda per-capita prevalecente hoje em dia em países como Portugal e Espanha. Dessa forma, podemos afirmar que a economia brasileira se encontra numa situação de semi-estagnação.

No final da década de 1980 e início da década de 1990, essa situação de semiestagnação era atribuída aos efeitos da inflação crônica que assolava a economia brasileira. Com efeito, em março de 1990, durante o último mês do governo Sarney, a inflação mensal foi de 72\%, caracterizando um quadro de hiper-inflação (cf. Bresser-Pereira, 2004, p.282). O final do processo hiper-inflacionário e a redução da taxa de inflação para um patamar de um dígito ao ano foram obtidos após a bem-sucedida implantação do Plano Real durante a administração do Presidente Fernando Henrique Cardoso, o qual se baseou, em larga medida, numa âncora cambial para a taxa de inflação.

A estabilização monetária não foi acompanhada, no entanto, por uma retomada do crescimento da economia brasileira a taxas mais vigorosas. A aceleração do crescimento econômico nos dois primeiros anos após a implantação do Plano Real - quando a taxa média de crescimento superou os 5\% anuais - foi logo interrompida em função dos efeitos

\footnotetext{
8 Professor do Departamento de Economia da UFPR, Diretor do Centro de Pesquisas Econômicas (CEPEC) da Universidade Federal do Paraná e Pesquisador nível I do CNPq. E-mail: joreiro@ufpr.br. Página Pessoal: www.joseluisoreiro.ecn.br.

${ }^{9}$ Professor do Departamento de Economia da UFPR, Chefe do Departamento de Economia da Universidade Federal do Paraná. E-mail: mcurado@ufpr.br.

10 Professor do Departamento de Economia da UFPR. E-mail: scatolin@ufpr.br.

11 Professor do Departamento de Economia da UFPR e Pesquisador nível I do CNPq. E-mail: porcile@ufpr.br.

12 Professor do Departamento de Economia da UFPR. E-mail: Luciano.nakabashi@ufpr.br.

13 Professor do Departamento de Economia da UFPR e da PUC/PR. E-mail: bplemos@uol.com.br.

${ }^{14}$ Professor das Faculdades Santa Cruz de Curitiba. E-mail: rod_padilha@yahoo.com.br.
} 
sucessivos das crises do México, Sudeste Asiático e Rússia. No início de 1999, após vários meses consecutivos de redução das reservas internacionais, devido a fuga de capitais motivada pela crise de confiança na sustentabilidade do regime cambial brasileiro após a crise da Rússia, o Brasil abandona o sistema de bandas cambiais em prol de um regime de flutuação da taxa de câmbio. O novo modelo macroeconômico é completado, ainda em 1999, com a adoção do sistema de metas de inflação e com a política de geração de expressivos superávits primários, destinados à estabilização da dívida pública interna como proporção do PIB.

O novo modelo macroeconômico permitiu uma expressiva redução da taxa real de juros - a qual passou de um patamar de cerca de 25\% a.a no período 1994-1998 para cerca de 10\% a.a. no período 1999-2005 - e uma desvalorização da taxa real de câmbio que foi de fundamental importância para a eliminação dos déficits crônicos em conta corrente observados no período 1994-1998, o quais chegaram a superar a marca de 4\% do PIB. Além disso, a política de geração de expressivos e crescentes superávits primários após 1999, permitiu que a dívida pública líquida como proporção do PIB entrasse numa trajetória (levemente) declinante, situando-se atualmente em cerca de 50\% do PIB.

Apesar da redução da taxa real de juros, da redução da vulnerabilidade externa e da estabilização da dívida pública, o desempenho da economia brasileira em termos de crescimento do PIB tem permanecido medíocre. A taxa média de crescimento no período 1999-2005 foi de apenas 2,3\% a.a contra uma média de 3,22\% no período 1994-1998.

Essas considerações nos permitem tirar duas conclusões fundamentais: a) a manutenção da taxa de inflação em patamares baixos e estáveis não é condição suficiente para a retomada do crescimento econômico em bases sustentáveis; b) a experiência brasileira mostra que a simples adoção de um modelo macroeconômico consistente - ou seja, um modelo de gestão da política macroeconômica que permita a obtenção de uma taxa de inflação baixa e estável, estabilidade da dívida pública como proporção do PIB e redução da vulnerabilidade externa - também não é condição suficiente para a retomada do crescimento.

Nesse contexto, a pergunta relevante a ser feita é: o que fazer para acelerar, de forma sustentável, o ritmo de crescimento da economia brasileira?

Existem duas respostas para essa pergunta. A primeira, baseada nos modelos de crescimento de inspiração neoclássica e na metodologia da contabilidade do crescimento, estabelece que a razão para o pífio crescimento da economia brasileira nos últimos 25 anos deve ser buscada no lado da oferta da economia. Mais especificamente, os problemas da economia brasileira seriam uma baixa taxa de poupança doméstica - devido a poupança 
negativa do setor público e ao baixo incentivo a poupança do setor privado em função da elevada carga tributária e do sistema de repartição vigente na previdência social brasileira - e um baixo dinamismo tecnológico expresso numa reduzida taxa de crescimento da produtividade total dos fatores de produção. Nesse contexto, a retomada do crescimento da economia brasileira a taxas mais expressivas exigiria uma reforma previdenciária que atuasse no sentido de aumentar a poupança do setor público e uma nova rodada de abertura comercial da economia brasileira com o intuito de estimular o crescimento da produtividade do trabalho nas empresas brasileiras.

A segunda resposta se baseia na idéia de que o modelo macroeconômico adotado pelo Brasil na última década atua no sentido de contrair a expansão da demanda agregada e, portanto, de impedir o crescimento do produto real. Isso porque a combinação de elevadas taxas reais de juros com a política de geração de superávits primários crescentes teria o efeito de deprimir a demanda agregada e, portanto, o crescimento do PIB. Nesse contexto, a solução para o problema de semi-estagnação existente na economia brasileira seria o abandono puro e simples do modelo macroeconômico vigente, baseado no tripé metas de inflação-câmbio flutuante-superávit primário.

Do nosso ponto de vista, as duas posições acima mencionadas são equivocadas. Antes de qualquer coisa, deve-se assinalar que rejeitamos a resposta baseada na metodologia da contabilidade do crescimento segundo a qual, na ausência de reformas do lado da oferta, a economia brasileira pode crescer, no máximo, a uma taxa de 3.5\% a.a no longo-prazo. O problema mais grave com esse procedimento é que o comportamento passado da economia passa a determinar as estimativas do seu crescimento potencial. Assim se o passado recente foi de lento crescimento então a "estimativa" da taxa de crescimento da produtividade total dos fatores de produção será baixa, "sinalizando" assim uma situação na qual o crescimento do produto potencial também é reduzido. Contudo, se o crescimento se acelerasse durante um período suficientemente longo de tempo (por exemplo, uns 10 anos), as estimativas do crescimento da produtividade total dos fatores de produção seriam revistas para cima e, conseqüentemente, aumentaria a taxa "estimada" de crescimento do produto potencial.

Dessa forma, acreditamos que os fatores que limitam o crescimento econômico no longo-prazo devem ser buscados no lado da demanda, não no lado da oferta da economia. Com efeito, testes econométricos realizados pelos autores mostram que 95\% do crescimento do PIB real no período 1990-2005 é explicado por variáveis do lado da demanda agregada da economia, corroborando a hipótese de crescimento puxado pela demanda agregada para a 
economia brasileira ${ }^{15}$. Nesse contexto, a economia brasileira teria enfrentado uma desaceleração no ritmo de crescimento no início dos anos 1980 devido ao esgotamento do padrão de expansão da demanda agregada vigente desde 1964, qual seja: a expansão dos gastos de consumo em bens duráveis de luxo viabilizada por uma crescente concentração de renda nas classes média e alta. Dessa forma, a semi-estagnação da economia brasileira resulta da inexistência, nas condições atuais, de um modelo consistente de expansão da demanda agregada.

No entanto, rejeitamos a visão keynesiana ingênua de que o crescimento pode ser estimulado por intermédio de qualquer política que aumente a demanda agregada. Os testes econométricos também mostraram que o multiplicador dos gastos de consumo corrente do governo é aproximadamente igual a 0,37 de tal forma que um aumento de $1 \%$ dos gastos de consumo corrente do governo irá resultar num aumento de $0,37 \%$ do PIB real brasileiro. Tomando-se como base uma carga tributária de cerca de 40\% do PIB, segue-se que um aumento de $1 \%$ dos gastos de consumo corrente do governo irá aumentar a receita tributária em apenas $0,15 \%$ do PIB. Daqui se segue que em função da crise fiscal do Estado Brasileiro, expressa pela combinação entre elevada dívida pública como proporção do PIB, carga tributária elevada e reduzido investimento público em obras de infra-estrutura; não é possível puxar o crescimento da economia brasileira por intermédio de uma política de expansão dos gastos de consumo corrente do governo. A única alternativa disponível é a adoção de um modelo de crescimento do tipo export-led.

A adoção desse modelo de crescimento requer, no entanto, um cuidado especial com o nível da taxa real de câmbio, uma vez que uma apreciação da taxa real de câmbio tende a gerar, no longo-prazo, um aumento da especialização produtiva da economia. Conforme demonstrado por Dosi, Pavitt e Soete (1990, cap.7) um aumento do grau de especialização produtiva da economia irá aumentar a sua propensão marginal a importar, aumentando assim o valor da elasticidade renda das importações, reduzindo, portanto, o valor da taxa de crescimento de equilíbrio de longo-prazo.

Nesse contexto, deve-se ressaltar que a evidência empírica disponível parece corroborar a tese de que os países menos desenvolvidos e, portanto, mais distantes da fronteira tecnológica tem se baseado numa taxa de câmbio mais depreciada para se manterem competitivos no comércio internacional e, dessa forma, assegurar um ritmo mais consistente

15 Ver Oreiro, Nakabashi e Lemos (2007).

30 
de crescimento das exportações. De fato, conforme podemos visualizar na figura 1 abaixo, parece existir uma relação inversa entre o gap tecnológico - medido pela relação entre o PIB per-capita do país e o PIB per-capita dos Estados Unidos - e o nível da taxa real de câmbio. $\mathrm{Na}$ figura 1 podemos observar também que o Brasil possui uma taxa de câmbio apreciada relativamente aos países que possuem o mesmo nível de gap tecnológico.

Figura 1 : Relação entre o Gap Tecnológico e a Taxa Real de Câmbio em Países Selecionados (19952005)

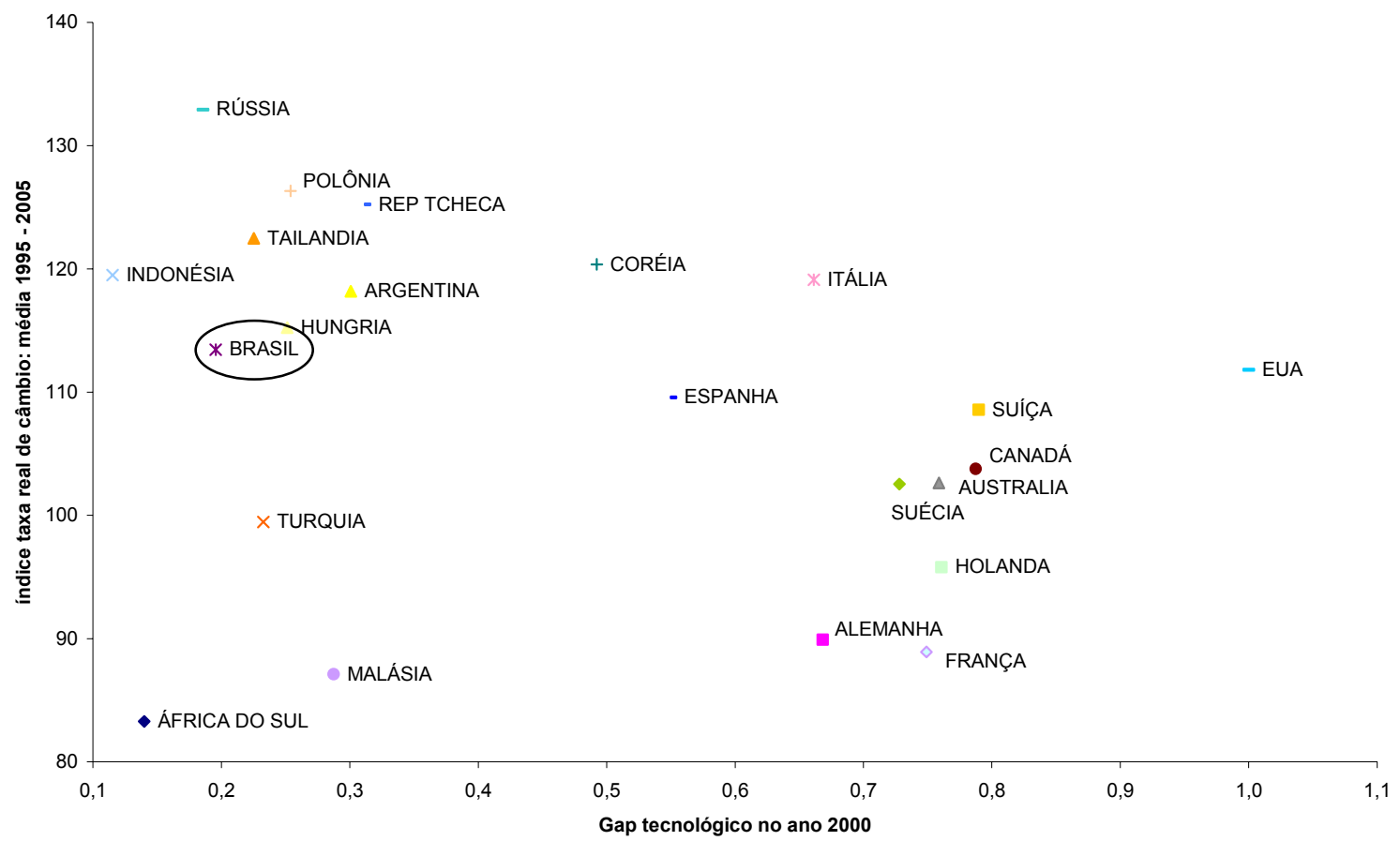

Fonte: International Financial Statistics. Elaboração Própria.

A necessidade de se gerar uma taxa de câmbio competitiva nos países mais distantes da fronteira tecnológica tem desdobramentos importantes sobre a condução da política monetária nesses países. Em particular, deve-se ter em mente que a fixação de uma meta de inflação muito baixa pode prejudicar o crescimento de longo-prazo à medida que gera uma apreciação da taxa real de câmbio. Em particular, nossas estimativas mostram que uma taxa de inflação inferior a 5,1\% a.a é claramente prejudicial ao crescimento econômico de longoprazo dos países emergentes (cf. Oreiro e Padilha, 2007). Segue-se, portanto, que a meta de inflação de longo-prazo para a economia brasileira deve se situar em torno de 5\% a.a. Dado que as expectativas de inflação para 2007 são de 4\%, o BCB tem um espaço enorme para a redução da taxa de juros sem abandonar o objetivo de manter a estabilidade da taxa de inflação no longo-prazo. 
Isso não significa, no entanto, que se possa aumentar a taxa de crescimento do PIB real com aumentos sucessivos da taxa de inflação. Tendo como base o trabalho de Sarel (1996), nossas estimativas empíricas mostram que a relação entre inflação e crescimento é não-linear, de tal forma que a partir de um certo patamar inflacionário, acréscimos da taxa de inflação geram uma redução da taxa de crescimento de longo-prazo.

A adoção de um modelo export-led growth exige também uma mudança na política cambial brasileira. Com efeito, tal como podemos observar na figura 2 abaixo, a adoção de um regime de flutuação cambial em janeiro de 1999 não foi suficiente para garantir a competitividade de médio-prazo da taxa real de câmbio. A taxa real efetiva de câmbio deflacionada pelo salário real médio pago na indústria brasileira alcançou no início do ano de 2006 os mesmos patamares observados durante o período de câmbio semi-fixo (1994-1998).

Figura 2 : Evolução da Razão Taxa Real Efetiva de Câmbio/Salário Real Médio da Indústria Brasileira (1994/01-2006/06)

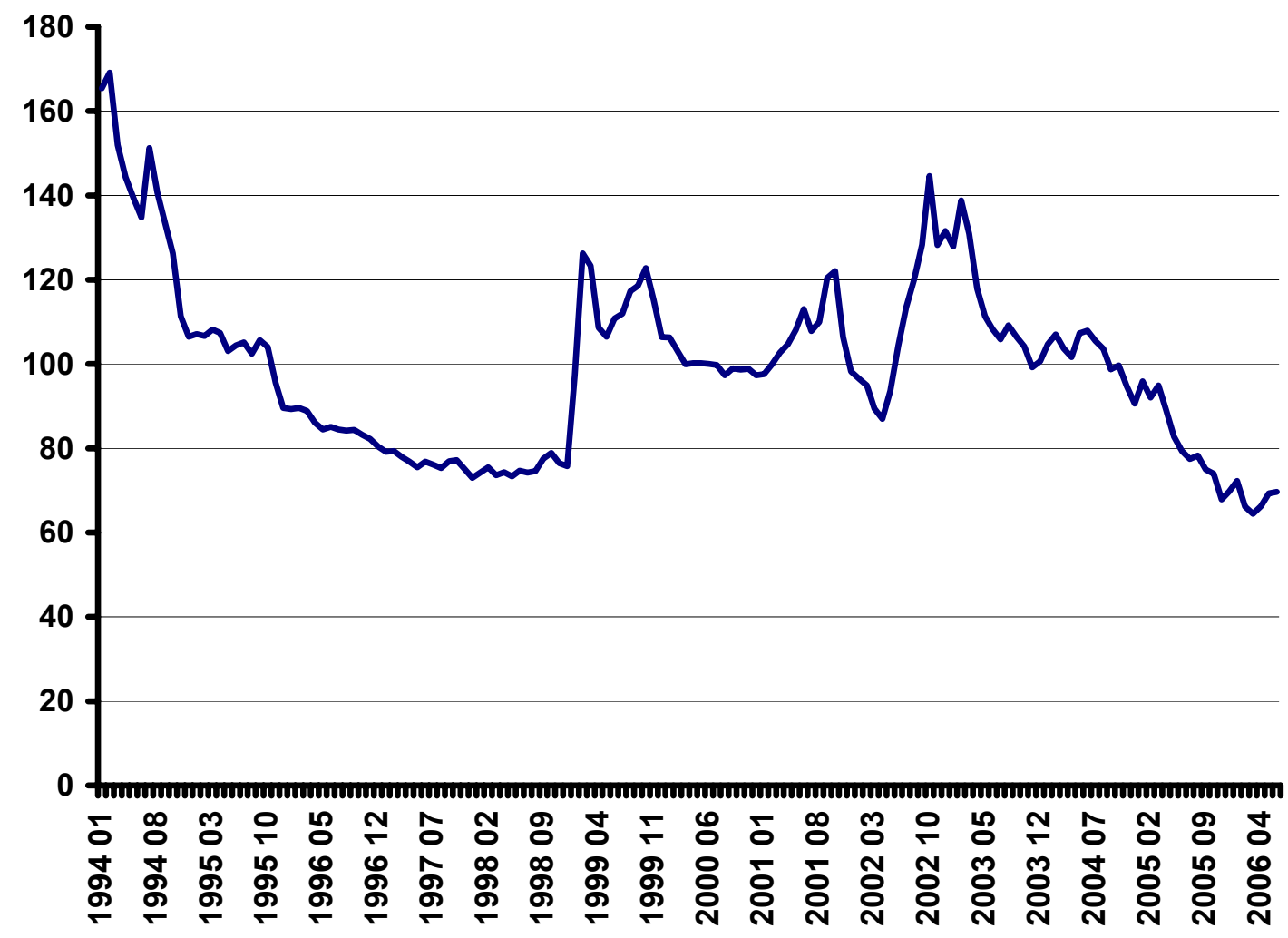

Fonte: IPEADATA. Taxa real de câmbio efetiva mensal-INPC - $(2000=100)$.

A mudança do regime cambial brasileiro não significa um retorno ao regime de câmbio semi-fixo adotado no período 1994-1998; mas sim a idéia de que as autoridades monetárias devem utilizar os instrumentos que tem a sua disposição para administrar a 
flutuação cambial. Um instrumento que as autoridades monetárias têm a sua disposição é a compra de reservas internacionais. Embora o Banco Central do Brasil tenha utilizado extensamente essa política nos últimos 18 meses, ainda existe um espaço considerável para o Brasil aumentar as suas reservas internacionais. Com efeito, as reservas internacionais do Brasil ainda estão baixas na comparação com outros países emergentes. Conforme se pode visualizar na figura 3 abaixo, no ano de 2004 o Brasil era um dos países que possuía a maior relação dívida externa de curto-prazo/reservas internacionais entre os países emergentes.

\section{Figura 3. Razão Dívida Externa de Curto-Prazo/Reservas Internacionais em Países Selecionados (1990-2004)}

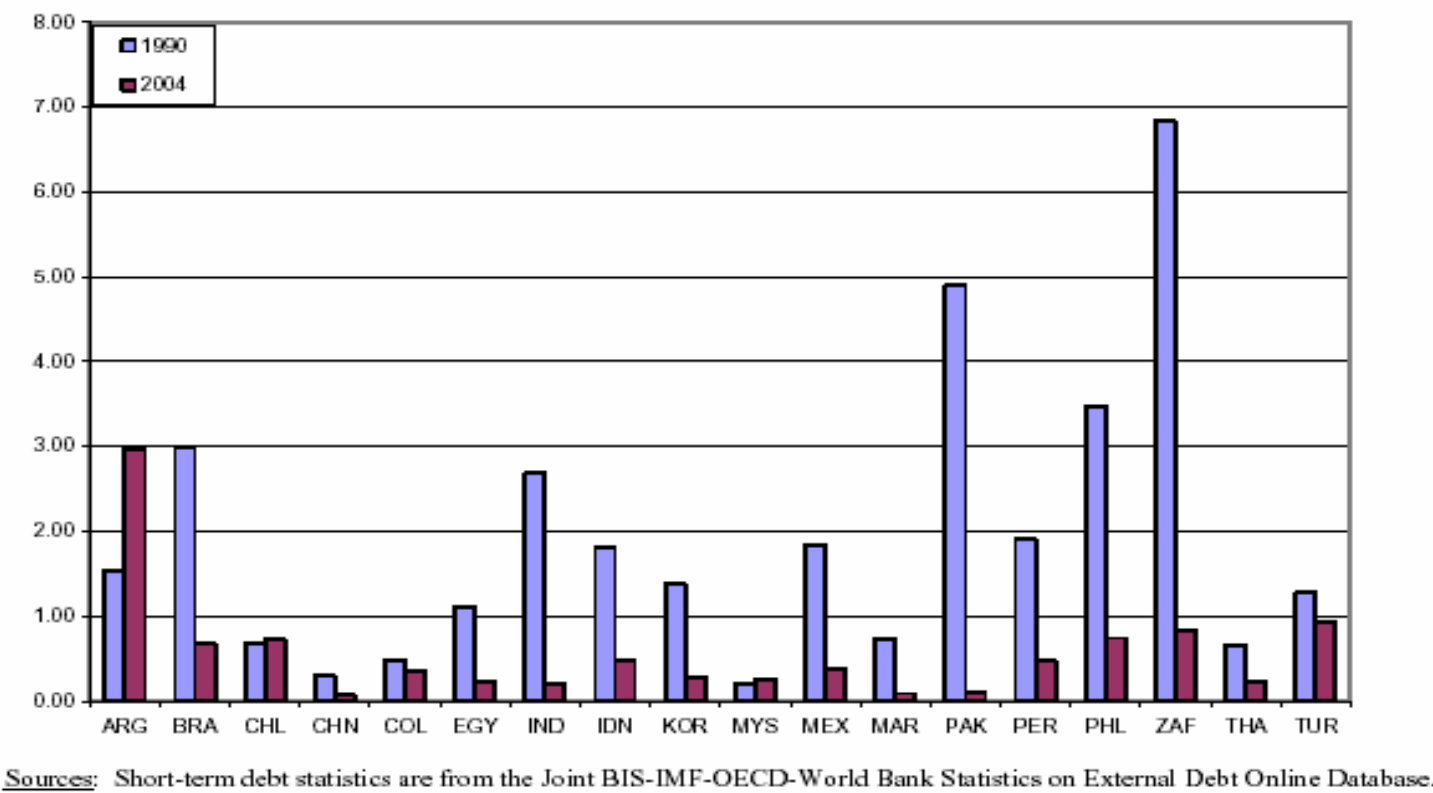

Uma proposta concreta no sentido de administrar a flutuação do câmbio seria a constituição de um "fundo de administração cambial" financiado com recursos provenientes da introdução de um imposto sobre o valor das exportações de produtos cujo valor no mercado internacional esteja elevado para os padrões históricos. Os recursos arrecadados com esse imposto seriam utilizados para financiar as operações de compra de reservas internacionais por parte do Banco Central do Brasil, ajudando assim a manter a competitividade de médio e longo-prazo da taxa real de câmbio.

Para reduzir o impacto inflacionário da transição de um câmbio apreciado para um câmbio competitivo deve-se aprofundar o ajuste fiscal brasileiro. De fato, a desvalorização da 
taxa nominal de câmbio requerida para a adoção de um modelo export-led deve ter um impacto temporário sobre os índices de inflação por intermédio do assim chamado efeito pass-through. Para reduzir esse efeito inflacionário, deve-se preceder a uma política de contração fiscal baseada no corte de gastos de consumo corrente do governo. Dessa forma, além de se minimizar o impacto inflacionário da desvalorização cambial, poderia ainda se abrir espaço nas contas do governo para um pequeno aumento dos gastos de investimento, os quais são essenciais para a eliminação dos gargalos de infra-estrutura existentes na economia brasileira.

Em resumo, nossos estudos apontam para as seguintes conclusões:

a) a manutenção da taxa de inflação em patamares baixos e estáveis não é condição suficiente para a retomada do crescimento econômico em bases sustentáveis;

b) a economia brasileira não está condenada a crescer a uma taxa de 3,5\% a.a, na ausência reformas microeconômicas. O problema mais grave com esse procedimento é que o comportamento passado da economia passa a determinar as estimativas do seu crescimento potencial.

Existem fortes evidências empíricas de que o crescimento da economia brasileira é puxado pela demanda agregada. Nossas estimativas mostram que 95\% do crescimento da economia brasileira no período 1990-2005 é explicado por variáveis do lado da demanda agregada da economia.

A crise fiscal do Estado Brasileiro - expressa pela combinação entre elevada carga tributária, elevada dívida pública como proporção do PIB e baixo investimento público em infra-estrutura - impede que o crescimento da economia brasileira possa ser puxado por uma expansão forte dos gastos de consumo corrente do governo.

Torna-se necessária a adoção de um novo modelo de desenvolvimento econômico, no qual o crescimento das exportações seja o elemento dinâmico da demanda agregada. Para tanto, deve-se evitar uma apreciação persistente da taxa real de câmbio, a qual pode aprofundar o grau de especialização produtiva da economia brasileira, aumentando a elasticidade renda das importações, com reflexos negativos sobre a taxa de crescimento compatível com o equilíbrio do balanço de pagamentos.

Uma das maneiras de evitar uma apreciação persistente da taxa real de câmbio é por intermédio de uma maior flexibilização do regime de metas de inflação. Em particular, o Banco Central deve evitar perseguir metas de inflação muito ambiciosas. Nossas estimativas mostram que uma taxa de inflação inferior a 5,1\% a.a é claramente prejudicial ao crescimento dos países emergentes. 
Assim sendo, a meta ótima de inflação para a economia brasileira é de 5\% a.a. Nesse contexto, o BCB tem um espaço considerável para reduzir a taxa nominal de juros sem abandonar os seus objetivos de manter a estabilidade da taxa de inflação no longo-prazo.

Faz-se necessária uma mudança na política cambial brasileira na direção de um regime de flutuação administrada da taxa de câmbio. Essa administração da taxa de câmbio pode ser conseguida por intermédio da constituição de um fundo de administração cambial, financiado com recursos provenientes da cobrança de um imposto sobre o valor exportado daqueles produtos cujos preços estiverem historicamente elevados nos mercados internacionais.

O impacto inflacionário de uma desvalorização da taxa nominal de câmbio pode ser minimizado por intermédio de um aprofundamento do ajuste fiscal brasileiro. Esse aprofundamento teria por base um corte dos gastos de consumo corrente do governo, abrindo assim um espaço para um pequeno aumento dos investimentos públicos em infraestrutura, os quais são essenciais para a eliminação dos gargalos de infra-estrutura existentes na economia brasileira.

\section{Referências Bibliográficas}

BRESSER-PEREIRA, L.C. (2004). Desenvolvimento e Crise no Brasil. Editora 34: São Paulo.

DOSI, G; PAVITT, K; SOETE, L. (1990). The Economics of Technical Change and International Trade. Macmillan Press: Londres.

OREIRO, J.L; NAKABASHI, L; LEMOS, B.P. (2007). "A Economia do Crescimento Puxado pela Demanda Agregada: Teoria e Aplicações ao Caso Brasileiro”. Texto para Discussão 01/2007. Departamento de Economia. Universidade Federal do Paraná.

OREIRO, J.L; PADILHA, R.A. (2007). “Inflação e Crescimento no Longo-prazo”. Valor Econômico, 22 de Janeiro, página A10.

SAREL, Michael (1996) "Nonlinear Effects of Inflation on Economic Growth" IMF Staff Papers, Vol. 43, no 1, p. 199-215. 
